\title{
Oxigenador extracorpóreo de membrana venoarterial como puente a la recuperación en choque cardiogénico resistente secundario a miocarditis fulminante por virus de la influenza $A$ complicada con taponamiento cardíaco
}

\author{
Venoarterial extracorporeal membrane oxygenation as a bridge to recovery in refractory \\ cardiogenic shock secondary to fulminant influenza A myocarditis complicated with \\ cardiac tamponade
}

César Jiménez-Méndez ${ }^{1 *}$, Pablo Díez-Villanueva ${ }^{1 *}$, Teresa Bastante ${ }^{1}$, Francisco de la Cuerda1,
Javier Segovia ${ }^{2}$ y Fernando Alfonso'
'Servicio de Cardiología, Hospital Universitario de la Princesa; ${ }^{2}$ Servicio de Cardiología, Hospital Universitario Puerta de Hierro. Madrid, España

La infección por el virus de la influenza tiene unas tasas de incidencia hasta de 350 casos/100,000 habitantes en el medio de los autores. Sin embargo, las miocarditis por el virus de la influenza son todavía una complicación infrecuente. Se presenta el caso de un varón de 35 años con antecedente de consumo de tabaco y cocaína ocasional, que consultó por dolor torácico pericárdico y clínica de infección respiratoria relacionada con serología positiva para virus de la influenza. El ecocardiograma inicial mostró disfunción ventricular grave (fracción de expulsión del ventrículo izquierdo; FEVI, 24\%) y derrame pericárdico leve. Dada la aparición progresiva del choque cardiogénico, requirió ingreso en la Unidad de Cuidados Cardiológicos Agudos con diagnóstico de miocarditis fulminante por virus de la influenza y se instituyó tratamiento con oseltamivir y apoyo vasoactivo con dobutamina y noradrenalina. A pesar de ello, y ante choque cardiogénico resistente (INTERMACS 1), se decidió implantar un dispositivo oxigenador de membrana extracorpóreo (ECMO) venoarterial, con lo que se consiguió mejoría de los parámetros hemodinámicos y analíticos. A las 12 horas del implante, el paciente experimentó un nuevo deterioro hemodinámico y el ecocardiograma reveló progresión del derrame pericárdico con signos de taponamiento cardíaco, por lo que se practicó pericardiocentesis urgente para mejorar la situación clínica. La evolución posterior fue buena, con mejoría progresiva de la función biventricular hasta su normalización y retiro del dispositivo al séptimo día. Este caso ilustra las complicaciones de mayor gravedad relacionadas con la miocarditis por influenza, como el choque cardiogénico progresivo y profundo, con disfunción biventricular complicada con taponamiento cardíaco; en éste se consiguió restablecer la situación hemodinámica gracias al implante temprano del ECMO-VA, se revirtió la situación catastrófica y se favoreció la recuperación al tratarse de un desencadenante agudo y potencialmente revertible. DOI: 10.24875/ACM.19000231 BY-NC-ND (http://creativecommons.org/licenses/by-nc-nd/4.0/).
Disponible en internet: 23-01-2020 Arch Cardiol Mex. 2020;90(2):233-235 www.archivoscardiologia.com 
La afectación cardíaca secundaria a infección por el virus de la gripe se puede presentar de distintas formas clínicas, desde pericarditis aguda hasta el taponamiento cardíaco o el síndrome de takotsubo".

Se presenta el caso de un varón de 35 años con antecedente de consumo de alcohol y cocaína, fumador habitual de tabaco y marihuana, que buscó atención por dolor torácico. Refería síntomas previos de tos, expectoración y mialgias difusas los últimos cinco días. Tres días antes del ingreso comenzó con dolor torácico punzante, irradiado hacia la espalda, que aumentaba con la inspiración y el decúbito, y empeoramiento clínico progresivo. A la exploración física destacaban taquicardia sinusal de 120 latidos por minuto, hipotensión arterial (presión arterial sistólica de $95 \mathrm{mmHg})$, febrícula $\left(37.5^{\circ} \mathrm{C}\right)$, así como frialdad cutánea, entre otros datos de hipoperfusión periférica.

Los análisis revelaron leucocitosis con neutrofilia

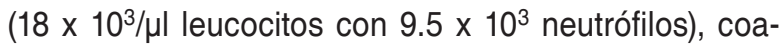
gulopatía (INR espontáneo, 1.4; APTT, 38 s; TP, 17.6 s), daño hepático (bilirrubina total, $2.46 \mathrm{mg} / \mathrm{dl} ; \mathrm{GOT} / \mathrm{AST}$, 86 UI/L; GPT/ALT, 85 UI/L; GGT, 107 UI/L; LDH, 310 $\mathrm{UI} / \mathrm{L}$; fosfatasa alcalina, $115 \mathrm{UI} / \mathrm{L}$ ) e hiperlactacidemia (láctico, $4.5 \mathrm{mg} / \mathrm{ml}$ ). El electrocardiograma mostró taquicardia sinusal sin alteraciones de la repolarización ni signos de isquemia aguda. Se realizó un ecocardiograma transtorácico que mostró un ventrículo izquierdo no dilatado (volumen telediastólico del ventrículo izquierdo, $45 \mathrm{~mm}$ ) con aspecto edematoso y espesores en el límite alto de normalidad (12 $\mathrm{mm}$ ) e hipocinesia global, lo que producía una función ventricular muy deprimida (fracción de expulsión del ventrículo izquierdo biplanar, FEVI, 25\%), Ilenado transmitral con fusión de ondas y elevación de presiones de llenado con relación $E / E^{\prime}$ de 16, función ventricular derecha conservada (TAPSE, $18 \mathrm{~mm}$; onda S', $12.5 \mathrm{~cm} / \mathrm{s}$ ), presión sistólica pulmonar de $45 \mathrm{mmHg}$ y derrame pericárdico leve (10 mm en pared libre del ventrículo derecho); no se observaron valvulopatías significativas. El paciente ingresó con diagnóstico de miocarditis aguda y la prueba del virus de la influenza $A$ resultó positiva y negativo el resto de las determinaciones microbiológicas, por lo que se inició tratamiento con oseltamivir.

Durante las primeras horas, el paciente presentó deterioro hemodinámico progresivo, con hipotensión y empeoramiento de la perfusión tisular (vigilancia con catéter de Swan-Ganz; PAM, 70 mmHg; FC, 130 lpm; GC, $3.1 \mathrm{~L} / \mathrm{min} ; \quad I C, 1.8 \mathrm{~L} / \mathrm{min} / \mathrm{m}^{2}$; PVC, 20; RVS, 1,290 dinas $/ \mathrm{m}^{2}$; saturación venosa central, $57 \%$ ), y oligoanuria, con necesidad de administrar dosis

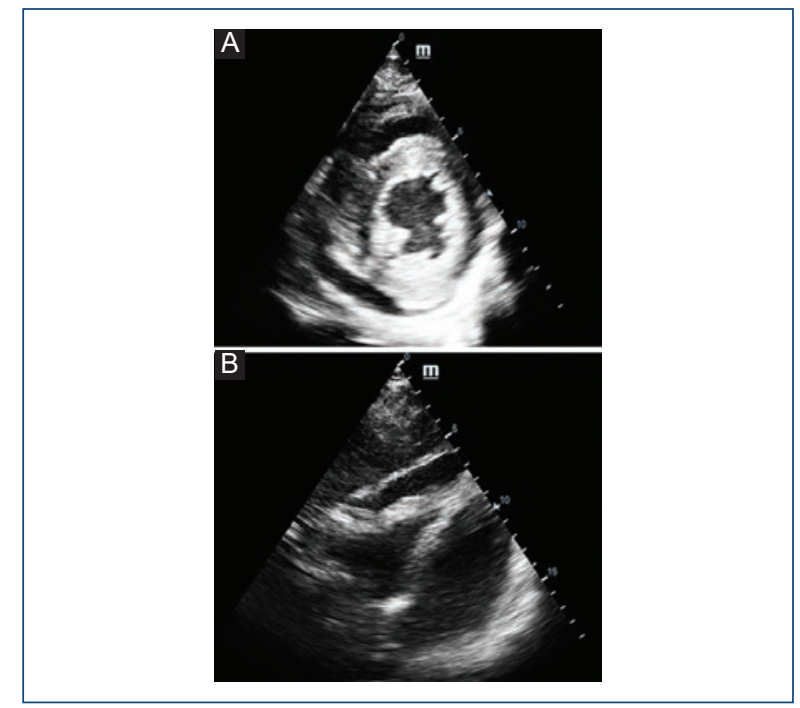

Figura 1. A: ecocardiograma transtorácico (plano paraesternal, eje corto) que revela un derrame pericárdico circunferencial. B: plano subcostal que delinea derrame pericárdico en la pared libre del ventrículo derecho.

crecientes de tratamiento vasoactivo con dobutamina y noradrenalina, así como intubación orotraqueal y apoyo ventilatorio. Pese a estas medidas, el paciente desarrolló aún signos de bajo gasto resistentes a las medidas instituidas; los ecocardiogramas seriados mostraron deterioro progresivo de la función biventricular (FEVI biplanar, 15\%; TAPSE, $10 \mathrm{~cm}$; onda S' de VD, $7.5 \mathrm{~cm} / \mathrm{s}$; FAC, 30\%). Ante el escenario de choque cardiogénico (critical cardiogenic shock) ${ }^{2}$ INTERMACS 1, se decidió el implante de asistencia ventricular tipo ECMO (extracorporeal membrane oxygenation) venoarterial (CARDIOHELPTM, MAQUET Cardiopulmonary AG, Alemania), gracias a lo cual se consiguió una rápida mejoría de los parámetros hemodinámicos, con recuperación de diuresis y cifras de los análisis, y corrección de la hiperlactacidemia hasta su normalización.

Después de 12 horas del implante del dispositivo, el paciente experimentó deterioro hemodinámico de rápida progresión, con elevación de la presión venosa central y atenuación del apoyo de la ECMO. El ecocardiograma reveló la presencia de derrame pericárdico grave con datos de taponamiento cardíaco (colapso parcial de la aurícula derecha, variación respiratoria del flujo transtricuspídeo del $45 \%$, vena cava inferior dilatada sin colapso respiratorio) (Fig. 1), así como la presencia de ecocontraste espontáneo en el interior de las cavidades izquierdas, en relación con elevación de presiones de llenado y aumento de la poscarga. En consecuencia, se realizó una pericardiocentesis evacuadora, que drenó $500 \mathrm{ml}$ de líquido seroso, un dato 


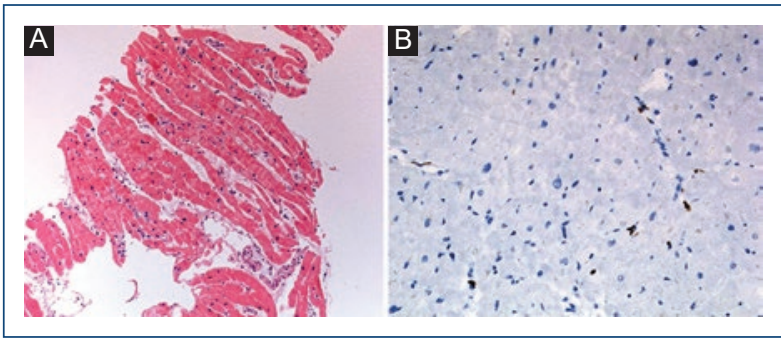

Figura 2. A: biopsia endomiocárdica que muestra infiltrado inflamatorio intersticial. B: biopsia endomiocárdica inmunohistoquímica que revela células CD3+ que infiltran el tejido.

consistente con exudado inflamatorio, y se implantó un balón de contrapulsación intraaórtico, lo cual contribuyó a mejorar la descarga ventricular. Con estas medidas, el paciente recuperó la estabilidad hemodinámica, que mantuvo durante los siguientes días y sólo requirió apoyo con noradrenalina por cierta vasoplejía (PAM, $55 \mathrm{mmHg}$; GC, $4.3 \mathrm{~L} / \mathrm{min}$; RVS, 800 dinas $/ \mathrm{m}^{2}$ ). La biopsia endomiocárdica mostró mínimo infiltrado inflamatorio (Fig. 2). La evolución posterior fue buena, con mejoría progresiva de la función biventricular hasta su normalización y el dispositivo se retiró al séptimo día. Con posterioridad pudo egresar bajo tratamiento médico optimizado.

Se han descrito en la bibliografía series de casos de miocarditis fulminante por el virus de la influenza, en especial en niños, la mayoría con presentación aguda y rápida progresión, sin que se conozcan por el momento los factores predisponentes ${ }^{3}$. Las asistencias circulatorias tipo ECMO-VA proporcionan apoyo hemodinámico y respiratorio, lo que asegura una adecuada perfusión periférica en pacientes con choque cardiogénico catastrófico y resistente a otras medidas (INTERMACS 1); es fundamental un implante temprano y preferente sobre otros dispositivos de asistencia circulatoria, en particular en caso de falla biventricular-6. El empleo de estos dispositivos ha contribuido a reducir la mortalidad en esta situación y pueden utilizarse como transición a la recuperación, como este caso, o bien como puente al trasplante cardíaco u otro tipo de asistencia ${ }^{6}$.

Este caso ilustra las complicaciones de mayor gravedad relacionadas con la miocarditis por influenza, como el choque cardiogénico progresivo y profundo, con disfunción biventricular grave y la aparición de derrame pericárdico progresivo, lo que da lugar al desarrollo de taponamiento cardíaco y el compromiso del llenado ventricular, y en este caso también el funcionamiento normal de la asistencia. El implante temprano del ECMO-VA consiguió restablecer la situación hemodinámica del paciente al revertir el choque cardiogénico en el que se encontraba y favorecer su recuperación al tratarse de un desencadenante agudo y potencialmente reversible $e^{4,5,7}$.

\section{Conflicto de intereses}

Los autores declaran no tener ningún conflicto de intereses.

\section{Financiamiento}

No se recibió ningún financiamiento.

\section{Responsabilidades éticas}

Protección de personas y animales. Los autores declaran que para esta investigación no se han realizado experimentos en seres humanos ni en animales.

Confidencialidad de los datos. Los autores declaran que han seguido los protocolos de su centro de trabajo sobre la publicación de datos de pacientes.

Derecho a la privacidad y consentimiento informado. Los autores han obtenido el consentimiento informado de los pacientes y/o sujetos referidos en el artículo. Este documento obra en poder del autor de correspondencia.

\section{Bibliografía}

1. Raisi Z, Mamas M. The cardiovascular manifestations of influenza: a systematic review. International Journal of Cardiology 2013:167:2397-2403.

2. Kirklin JK, Naftel DC, Stevenson LW, Kormos RL, Pagani FD, Miller MA, et al. INTERMACS database for durable devices for circulatory support: first annualreport. J Heart Lung Transplant. 2008;27:1065-72.

3. Cárdenes A, Gallardo E, Prada R, López M, Martin PL. Shock cardiogénico y taponamiento cardiaco en el contexto de la miopericarditis por influenza A. Rev Esp Cardiol. 2017;70(12):1139-1151.

4. Díez-Villanueva P, Sousa I, Núñez A, Díez F, Elízaga J, Fernández-Avilés $F$. Early treatment of refractory cardiogenic shock with percutaneous veno-arterial ECMO implanted in the cardiac catheterization laboratory. Rev Esp Cardiol (engl ed). 2014;67(12):1059-61.

5. Hekimian G, Jovanovic T, Bréchot N, Lebreton G, Leprince P, Trouillet $\mathrm{JL}$, et al. When the heart gets the flu: fulminant influenza B myocarditis: a case-series report and review of the literature. J Crit Care. 2018;47:61-64.

6. Guglin M, Zucker M, Bazan V, Bozkurt B, El Banayosy A, Estep JD, et al. Venoarterial ECMO for adults. Journal of the American College of Cardiology. 2019;73(6):698-716.

7. Martin-Villen L, Martin-Bermúdez R. ECMO: past, present and future in critical care. Med Intensiva. 2017;41(9):511-512. 